\title{
El examen MIR, su cambio como una opción estratégica
}

\author{
G. Vázqueza , F. Murillo-Cabezas b, J. Gómezc , C. Martínc, J. Chavesa , J.L. Peinado c
}

El examen MIR es un punto estratégico capaz de promover cambios en cascada en su entorno, con repercusiones tanto en la etapa de licenciatura como en la de especialización. Actualmente, la implantación de un nuevo currículo basado en competencias y las nuevas metodologías de entrenamiento y evaluación, aconsejan adecuar el examen MIR a las necesidades actuales. El rediseño del examen MIR requiere incrementar el número de preguntas y apoyarlas con iconografía, y relacionarlas con competencias predeterminadas, a la vez que se incorpora la evaluación objetiva de habilidades. Este cambio requiere más tiempo para realizar los exámenes, una gestión más ágil, equipos multidisciplinares de diseño y centros acreditados. El soporte informático debe dar cobertura al 100\% de las actividades del examen MIR. La equidad, la transparencia y la accesibilidad deben ser los valores del examen MIR.

Palabras clave. ECOE. Evaluación de competencias. Examen MIR. Facultades de medicina. Opción estrategia. Residentes.

\section{The MIR examination, the change as a strategic option}

The MIR examination constitutes a strategic point which is capable of promoting cascading changes in its environment with repercussions at both the undergraduate and specialisation stages. At present, the implementation of a new skills-based syllabus and new training and evaluation methodologies make it necessary to adapt the MIR examination to current needs. The redesign of the MIR examination requires an increase in the number of questions; these must be supported with iconography and related to predetermined competences along with the incorporation of objective skills evaluation. This change requires more examination time, more efficient management, multi- disciplinary design teams and accredited centres. Information technology support must provide 100\% cover to the MIR examination activities. Equity, transparency and accessibility must be the values of the MIR examination.

Key words. Assessment of competencies. MIR examination. OSCE. Residents. Schools of medicine. Strategic option.

\section{Introducción}

El examen MIR es posiblemente un punto estratégico en la vida profesional de los médicos, con una de las mayores potencialidades de promover cambios en cascada en su entorno, con repercusiones tanto en la etapa de licenciatura como en la de especialización.

La estructura del examen MIR es simple y se basa en una prueba de respuestas múltiples, que tiene como valor añadido ser una prueba objetiva que permite asignar una clasificación a los examinados según el número de aciertos obtenidos; su infraestructura corresponde a una prueba escrita realizada simultáneamente en varios puntos de España, con las máximas garantías de transparencia [1].

La puntuación obtenida en la prueba permite a los médicos seleccionar hospitales y especialidades. En el momento actual convergen sobre el examen MIR diversas situaciones que hacen aconsejable la revisión de los objetivos y el formato de éste.

Nuestro objetivo es analizar esta perspectiva del examen MIR, por lo que se triangularán la información procedente de diversas fuentes. a Fundación IAVANTE. Granada.

b Hospital Universitario Virgen del Rocío. Sevilla.

c Facultad de Medicina. Universidad de Granada. Granada, España.

Correspondencia Dr. Guillermo Vázquez. Director de I+ D. Fundación IAVANTE. Consejería de Salud, Andalucía.

Parque Tecnológico Ciencias de la Salud. Avda. de la Ciencia, $\mathrm{s} / \mathrm{n}$ E-18100 Armilla (Granada).

E-mail

guillermo.vazquez@ iavante.es 


\section{El examen MIR desde la perspectiva de un análisis DAFO}

El análisis DAFO (debilidades, amenazas, fortalezas y oportunidades) es una metodología cualitativa utilizada para obtener una visión global de los factores que definen una situación o un proyecto [2]. En medicina se utiliza para analizar campos donde múltiples influencias actúan simultáneamente, y hacen difícil otro tipo de análisis. En este análisis, los conceptos de oportunidades y amenazas se refieren a factores externos, mientras que los conceptos de fortalezas y debilidades se deben a factores internos. En la tabla se recoge un DAFO del examen MIR, donde se recogen las opiniones de expertos expresadas a lo largo de diversas reuniones sobre educación médica.

Las oportunidades que se detectan en el entorno del examen MIR se centran en el nuevo programa de licenciatura que el colegio de decanos de España ha propuesto. En éste se profundiza el desarrollo en competencias y se recogen nuevos dominios transversales como la comunicación. Paralelamente, la existencia de nuevas metodologías educativas, tales como la simulación en sus diversas variantes o el aprendizaje basado en problemas, facilitan trabajar y evaluar competencias durante la licenciatura.

La amenaza principal, pero no la única, proviene de proveedores externos a las facultades de medicina; éstos aprovechan el impacto de este examen sobre el futuro de los médicos, y que la memorización es el aspecto clave del examen MIR, para iniciar su preparación incluso desde cuarto de carrera; el abandono de las aulas de medicina es una consecuencia de esta presión externa a las facultades, así como el desinterés por las prácticas en los hospitales. Este descrédito también se refleja en la normativa reciente, que impide que el médico residente de primer año no pueda tomar decisiones clínicas no visadas, lo cual le convierte o mantiene en un estado de alumno retribuido.

Los puntos fuertes giran alrededor de su carácter estatal, es decir, su incidencia en todo el colectivo médico. Por tanto, cualquier tipo de cambio que se introduzca en el examen MIR facilitará que las facultades de medicina adopten nuevas metodologías docentes o que los estudiantes tengan que participar en sus actividades.
Tabla. DAFO ${ }^{a}$, examen MIR.

Oportunidades

- Nueva propuesta de licenciatura médica

- Nuevas metodologías de formación y entrenamiento

- Tecnologías de la información y comunicación

Amenazas

- El estudiante centra sus estudios en el examen MIR

- La preparación MIR se hace con proveedores externos

Puntos fuertes

- Afecta a todo el colectivo médico

- Transparencia, equidad y accesibilidad

Puntos débiles

- Sólo analiza algunos aspectos cognitivos

- La validez no es óptima a causa del número de preguntas que contiene

- Los hospitales son receptores pasivos

- Los exámenes tienen un formato escrito clásico

a Debilidades, amenazas, fortalezas y oportunidades. Este análisis, basado en la opinión de expertos, identifica los diversos componentes que influyen y rodean el examen MIR.

Los puntos débiles se deben a que en su diseño actual sólo analiza los eslabones cognitivos; potencia la memorización como eje sobre el que se basa la preparación del examen MIR. Posiblemente, no es un buen reflejo de los conocimientos y en absoluto de las habilidades que un profesional debe poseer para iniciar su actividad como médico.

\section{El examen MIR en las bases bibliográficas}

La búsqueda en Medline utilizando la palabra clave MIR localizada en el título y/o abstract y escrito en español, identifica 42 trabajos, de los cuales sólo seis tienen la palabra MIR en el título; en la base de datos Scielo, la palabra MIR sólo proporciona dos trabajos, mientras que la Biblioteca Cochrane Plus localiza indirectamente dos trabajos. Dada la escasa trazabilidad bibliográfica de la palabra MIR, se puede con- 
siderar que este examen no ha constituido un tema de interés para la comunidad científica; esto ha privado a los profesores de unas bases objetivas sobre las que fundamentar sus acciones educativas $y$, por ende, para preparar el examen MIR.

A pesar de la escasez de publicaciones, algunas de ellas aportan una visión interesante del examen MIR. En relación con la metodología de respuestas múltiples del MIR, el Estudio COMBELL [3] pone de manifiesto una de las carencias fundamentales del mismo, la falta de correlación entre las competencias medidas con este tipo de exámenes y las competencias medidas con enfermos simulados o bien con imágenes clínicas. Algunos artículos escritos por expertos en educación médica identificaron, ahora hace ya más de 15 años, la memorización como eje principal del examen MIR, situación que ha persistido hasta nuestras fechas $[4,5]$. Otros trabajos más actuales insisten en la pérdida de su capacidad discriminatoria, dado que no es excepcional que en las convocatorias de los últimos años queden plazas vacantes [6], mientras que otros artículos basados en modelos matemáticos de simulación predicen una gran disfunción entre las necesidades asistenciales de la población y la necesidad de especialistas que generará nuestro modelo actual de MIR [7]. Los problemas del examen MIR, aunque son conocidos desde hace tiempo, no han conllevado medidas correctoras.

\section{Contenidos del examen MIR}

Los estudios sobre los contenidos del examen MIR no suelen ir mas allá del análisis cuantitativo de repartición de preguntas por asignaturas e incluso así son escasos. Análisis cualitativos del examen MIR, y la opinión de los expertos en los congresos de la Sociedad Española de Educación Médica, coinciden en señalar que la distribución de las preguntas responde predominantemente a una estrategia cuantitativa de reparto de materias y no a un análisis de competencias médicas predeterminadas, con más del $60 \%$ de las preguntas con base memorística [8]. Otras características que cabe recalcar son las siguientes: las materias imprescindibles en la formación médica actual (p. ej., emergencias, bioética, medicina de familia, salud comunitaria, gestión clínica) son mar- ginales; no se incorpora a las preguntas material tipo gráficas, tablas o imágenes, y no se evalúan habilidades dado que las simulaciones (p. ej., examen clínico objetivo estructurado, ECOE) no están previstas [1]. El examen se hace en formato escrito clásico en una convocatoria única, lo cual revela la falta de alternativas modernas con las que afrontar este tipo de evaluaciones. Finalmente, existe la duda razonable sobre si 250 preguntas tienen la validez adecuada para identificar el conjunto de conocimientos que deben evaluarse en un profesional transcurridos 6 años de formación universitaria [9].

La combinación de todos estos factores explica en buena parte el abandono de las aulas para preparar el examen MIR; tampoco podemos olvidar que la carga lectiva de las facultades, basada predominantemente en clases magistrales, puede influir en dicho abandono, ya que este tipo de clases pueden ser sustituidas por apuntes o libros.

Comparar nuestro MIR con el examen que se realiza en Estados Unidos (United State Medical Licensing Examination, USMLE) [9], con la misma finalidad, puede ayudar a visualizar la posibilidad de otros modelos de evaluación. El USMLE está constituido por tres etapas distintas: la primera está centrada en las ciencias básicas aplicadas a problemas clínicos; la segunda etapa evalúa el conjunto de conocimientos y habilidades necesarios para la práctica clínica, y la tercera etapa evalúa la práctica clínica que un médico general debe poder afrontar en su etapa inicial. En conjunto, tiene alrededor de 1.200 preguntas, 11 estaciones con enfermos simulados y 20 casos clínicos completos desarrollados por ordenador. En total se requieren cinco días, con jornadas de ocho horas. No existe una prueba única y simultánea, sino que los candidatos disponen de un año para pasar las etapas mencionadas. Centros acreditados para los exámenes de preguntas no sólo en EE.UU. sino también en otros países, junto con centros específicos para ECOE en EE.UU., dotan al examen de accesibilidad y factibilidad. La validez, reproducibilidad y dificultad equivalente, aseguran la equidad de los exámenes. La gestión y los exámenes del USMLE se realizan al $100 \%$ por ordenador. (Obviamente, los ECOE son presenciales.) Una vez pasado el USMLE, los mejores candidatos serán llamados por los mejores hospitales, que participarán activamente en la selección de sus residentes. 


\section{El rediseño posible del examen MIR}

El examen MIR ha tenido un papel relevante en la modernización de la medicina de nuestro país. También debe reseñarse la calidad de su formato y haber asegurado equidad y transparencia. Estos valores deben preservarse, pero a lo largo de esta exposición hemos intentado destacar la necesidad de un cambio profundo, en un momento en que las condiciones externas son favorables. La concepción del examen MIR como un punto estratégico capaz de generar cambios en cascada en su entorno debería convertir su rediseño en una prioridad para apoyar la modernización de nuestras estructuras educativas y sanitarias. Pasar la página a la influencia negativa de su formato actual y convertir la investigación en educación médica en un objetivo equiparable a otras áreas de investigación serían también necesidades inaplazables.

Si la misión del examen MIR es catalogar por niveles de memorización a los concursantes, el examen puede seguir igual, y se aceptan sus efectos negativos sobre la carrera de medicina; si el examen debe catalogar a los candidatos por su conocimiento crítico y reflexivo, y por una práctica clínica básica adecuada, el examen MIR debe variar. El número de preguntas debe incrementarse, su formato iconográfico mejorarse y la simulación debe ser una de sus partes integrantes. Tanto el examen como sus infraestructuras deben de estar informatizados.

Para que el cambio de formato sea factible es necesario crear estructuras que le den sostenibilidad, a la vez que preservan los valores centrales del examen MIR. Esto requiere en primer lugar una red de centros acreditados, dotados con aulas informatizadas para realizar el examen MIR; su implantación geográfica debe ser adecuada; un campus virtual debe permitir la interconexión de todos los centros para hacer el examen. Es posible, que al igual que el USMLE, estos centros puedan acreditarse en otros países. En segundo lugar, centros con espacios escénicos diseñados específicamente para realizar ECOE; el número de estos centros sería, por fuerza, limitado a causa de la infraestructura que requieren. Paralelamente debe existir una estructura docente estable que asegure la validez, reproducibilidad y equivalencia de todas las actividades evaluadoras, así como su funcionamiento permanente a lo largo del año, con convocatorias abiertas perma- nentemente. El organismo responsable del examen MIR debe acoger como pares instituciones gubernamentales, universitarias y científicas. Un buen ejemplo de estructura docente innovadora capaz de dar respuesta al examen MIR del siglo xxi es el Centro Multifuncional de Simulación Avanzada que la Consejería de Salud de Andalucía tiene en Granada, perteneciente a la Fundación IAVANTE [10]; la misión de esta fundación es la transferencia, entrenamiento y evaluación del conocimiento y habilidades que requieren los profesionales sanitarios andaluces.

La financiación de estos centros requiere dotaciones presupuestarias altas, que pueden abordarse desde diversas opciones para minimizar su coste; en cualquier caso, los beneficios que pueden generarse, tanto en términos de cambio de cultura médica como en términos de potenciación de sociedad del conocimiento, lo justifican.

\section{Bibliografía}

1. Programas de Formación Sanitaria Especializada. Ministerio de Sanidad y Consumo. URL: http://sis.msc.es [19.10.2008].

2. Gordon J, Hazlett C, Ten Cate O, Mann K, Kilminster S, Prince K, et al. Strategic planning in medical education: enhancing the learning environment for students in clinical settings. Med Educ 2000; 34: 841-50.

3. Gómez-Sáez JM, Pujol-Farriols R, Martínez-Carretero JM, Blay-Pueyo C, Jaurrieta-Mas E, Friedman M, et al. El proyecto COMBELL. Un análisis de la competencia clínica médica. Med Clin (Barc) 1995; 105: 649-51.

4. Rozman C. La educación médica en el umbral del siglo xxi. Med Clin (Barc) 1997; 108: 582-6.

5. Rozman C. La enseñanza de la medicina, ¿debe cambiar de modelo? Med Clin (Barc) 1993; 100 (Supl 1): S3-5.

6. Casado-Vicente V. El examen MIR y las plazas de médico de familia. Aten Primaria 2006; 38: 535-6. |

7. Alonso MI. La gestión del proceso de convocatoria de plazas de formación médica especializada. Gac Sanit 2003; 17: 289-95.

8. VázquezG,GómezJ,MartínC,ChavesJ,PeinadoJM.Elexamen MIR analizado cualitativamente. Educ Med 2007; 10; 176.

9. United Status Medical Licensing Examination. URL: http://www.usmle.org [19.10.2008].

10. Fundación IAVANTE. Consejería de Sanidad, Junta de Andalucía. URL: http://www.iavantefundacion.com/ [19.10.2008]. 